\title{
Neuroinformatics in the Time of Coronavirus
}

\author{
Giorgio A. Ascoli ${ }^{1}$
}

Published online: 29 June 2020

(C) Springer Science+Business Media, LLC, part of Springer Nature 2020

Some years ago, I received an inquiry from an international $\mathrm{PhD}$ student from the lab of a known electrophysiologist. ${ }^{1}$ She had secured a fellowship that allowed her to spend time in another lab during her doctoral training and she wanted to come to my lab to learn the neuroinformatics trade. I interviewed her in person at the Society for Neuroscience meeting a few weeks later and asked her why, after investing half a decade mastering advanced skills in patch clamp and intraneuronal recordings, she wanted to jump into neuroinformatics. She was adamant in saying that she saw a shrinking market for experimental research, at least in relative terms, and a growing role for data science. She also thought it would become increasingly difficult, on economic, social, and personnel counts, to eventually create and maintain a wet lab centered on animal research, and to keep it productive. Just as many discoveries awaited, she felt, in big data, informatics, computer analytics, and modeling - and that sounded to her like a wiser and more appealing career prospect.

When she started her 4-month visit in my lab, I asked her if she had additional goals for her internship besides neuroinformatics training. "Yes", she said, "convincing you I'm so good that you'll want to hire me as a postdoc when I graduate". Fast-forward to March 2020 - her mission accomplished, now a successful neuroinformatics postdoc in my lab... but in the midst of a global pandemic progressively grinding the majority of the planet to a halt. All around us wet labs shutting down, graduate students

\footnotetext{
${ }^{1}$ A version of this writing was submitted on May 20, 2020 to the NITRC Quarterly Newsletter as a News Item post.
}

Giorgio A. Ascoli

ascoli@gmu.edu

1 Center for Neural Informatics, Structures, and Plasticity; Bioengineering Department; and Neurocience Program; Krasnow Institute for Advanced Study and Volgenau School of Engineering, George Mason University, Fairfax, VA, USA delaying their dissertation defenses 'til they could complete their last experiment, Principal Investigators requesting no-cost extensions for their grants and dipping into their discretionary rainy day funds to keep their staff on the payroll - a devastating cataclysm for academic research, not to mention the many colleagues and acquaintances directly or indirectly affected by the illness.

Yet our lab resembled a miraculous oasis, a shielded bubble: in a matter of days, our operation was able to transform completely and seamlessly into a fully functional remote working environment. A couple of trainees had to electronically sign a form to haul their office desktops home. But most of our computing equipment had long moved to a dedicated research computing building, and we had been routinely accessing our servers and databases through a virtual private network well before the time of coronavirus. In fact, for several years many in our lab enjoyed telecommuting at least one day per week (and often more) in order to optimize family, logistic, economic, environmental, and time-management constraints. So, it is fair to say that the professional impact of the stayhome orders on our lab have been minimal; the only substantial difference being the awkward transition to zoombased lab meetings. Even that is now growing as second nature, and it might be hard to shake the habit when the emergency is over.

Practically nobody imagined the unprecedented events of the first half of 2020, not even my farsighted postdoctoral associate. Nevertheless, she had the wisdom to recognize the tremendous potential and practical benefits of neuroinformatics. With physical distancing mandates and limited mobility, this is an even better time than usual for all brain researchers to discover or rediscover the myriads of excellent electronic tools and online resources to tackle your favorite open neuroscience problems. There is a lot to explore in the public domain - from non-invasive human neuroimaging databases to neuronal modeling software; from knowledge bases of neural architectures to multimodal electronic atlases; from very-large-scale 
whole-genome transcriptomic maps to comprehensive resources for cognitive and behavioral investigations. My personal favorites are NeuroMorpho.Org ${ }^{2,3}$ the evergrowing repository of digital reconstructions of axonal, dendritic, and glial morphology, and Hippocampome. $\mathrm{org}^{4,5}$ the go-to resource for hippocampal neuron types, properties, and circuitry... but I will readily admit my bias here. A great starting place to judge for yourself? Why, the Table of Content of this journal ${ }^{6}$ of course.
You will find lots of useful goodies there to boost or reboot your science. If you get started now, I bet you will continue to use them long after Covid19 will have faded into a memory of the past.

Publisher's Note Springer Nature remains neutral with regard to jurisdictional claims in published maps and institutional affiliations.

\footnotetext{
${ }^{2}$ Halavi M, Polavaram S, Donohue DE, Hamilton G, Hoyt J, Smith KP, Ascoli GA: NeuroMorpho.Org Implementation of Digital Neuroscience: Dense Coverage and Integration with the NIF. Neuroinformatics 6, 241 (2008). https://doi.org/10.1007/s12021-008-9030-1

${ }^{3}$ Akram M, Nanda S, Maraver P, Armananzas R, Ascoli GA: An open repository for single-cell reconstructions of the brain forest. Sci Data 5, 180,006 (2018). https://doi.org/10.1038/sdata.2018.6

${ }^{4}$ Wheeler DW, White CM, Rees CL, Komendantov AO, Hamilton DJ, Ascoli GA: Hippocampome.org: a knowledge base of neuron types in the rodent hippocampus. eLife 2015;4:e9960 DOI: https://doi.org/10.7554/eLife.09960

${ }^{5}$ Ascoli GA: The coming of age of the hippocampome. Neuroinformatics 8 (1), 1-3 (2010)

${ }^{6} \mathrm{https}: / /$ www.springer.com/journal/12021/
} 